\title{
Effective binder based on the artificial anhydrite for manufacturing of filling mixtures
}

\author{
Nadezda Galtseva ${ }^{1, *}$ and Anfisa Bogdanova ${ }^{1}$ \\ ${ }^{1}$ Moscow State University of Civil Engineering, Yaroslavskoye sh., 26, 129337, Moscow, Russia
}

\begin{abstract}
The article exposes the results of research on the development of filling mixtures based on artificial anhydrite obtained after the interaction of concentrated sulfuric acid and limestone flour. The anhydrite derivation method has a significant impact on its properties and brings more options for the application. The key features of artificial anhydrite are high compressive strength which is more than $50 \mathrm{MPa}$ and extended setting time which is more than 10 hours. In order to use it as a binder in the filling mixtures, it is necessary to modify properties of the anhydrite by integrating the hardening activators. In the relation to the study it was found that the optimal activator providing desirable setting start time (at least 2 hours) and a sufficient set of strength in the first 7 days of hardening is a mixture of 5\% portland cement CEM I 42,5 and $1 \%$ of potassium sulfate, where $100 \%$ is the mass of binder. The additional inclusion of Melment F10 plasticizer in the amount of 0.4 to $1 \%$ of the binder ensures the achievement of the such parameters as the 0.3 waterbinder ratio, setting start from 120 to $225 \mathrm{~min}$, final setting time from 180 to $355 \mathrm{~min}$, compressive strength after 24 hours from 6.9 to $13.3 \mathrm{MPa}$, after 7 days from 24.0 to $33.5 \mathrm{MPa}$. The microstructure of the binder has been analyzed and the modification options of the artificial anhydrite have been revealed in order to regulate its technical and technological properties., Two compounds of the filling mixture have been developed on the basis of the obtained binder, technical properties of compounds satisfy the maximum requirements for filling materials for depleted underground spaces. Research results have shown an opportunity and a prospectively of integrating the modified artificial anhydrite in structures of filling mixtures.
\end{abstract}

\section{Introduction}

The surplus of sulfuric acid at non-ferrous metallurgy enterprises increases the importance of searching for new (alternative) methods for its utilization, one of which is the treatment with calcium-containing neutralizing agents like limestone, chalk, lime and lime milk, which results in obtaining various modifications of calcium sulfate that can be used as gypsum binders [1-3].

\footnotetext{
*Corresponding author: nadya@galtsev.com
} 
The existing methods of neutralizing the sulfuric acid presume sophisticated technological processes, low manufacturability, engineering complexity and also heavy economic expenditures.

At the moment, a new preparation method for the artificial anhydrite has been developed using strongly acid solutions, as a result of the interaction of sulfuric acid with limestone flour. The phase composition of calcium sulfate corresponds to insoluble anhydrite. Drawback of the obtained artificial anhydrite is its low reactivity. One of the most promising areas for the future use of artificial anhydrite is the use in filling mixtures, the production and use of which could solve the utilization problem of concentrated sulfuric acid and create an effective competitive analogue of the materials which are currently in use that also satisfies technical and technological requirements [4-8].

\section{Experimental}

The applicability of artificial anhydrite for filling mixtures was determined by physical and mechanical parameters including comparison with similar values for natural and thermal anhydrite (obtained by heat treatment of gypsum stone).

Researches of the effect of hardening catalysts such as potassium sulfate, portland cement and plasticizing surfactants were carried out, also properties of natural, thermal and artificial anhydrite with these catalysts were analyzed. Compressive strength dependency on the concentration of lime and potassium sulfate was obtained, and the degree of hydration dependency on the concentration of lime and potassium sulfate were established, which corresponds with the data of leading scientists in the field of gypsum materials [9$12]$.

The comparative analysis of the results of studying natural, thermal and artificial anhydrites, shown in Figures 1 and 2, revealed that the setting time for thermal and artificial anhydrite is longer than that of natural one, and their strength is much higher. The compressive strength of solidified thermal anhydrite is twice as much as of natural one, and the compressive strength of artificial anhydrite is three times higher.

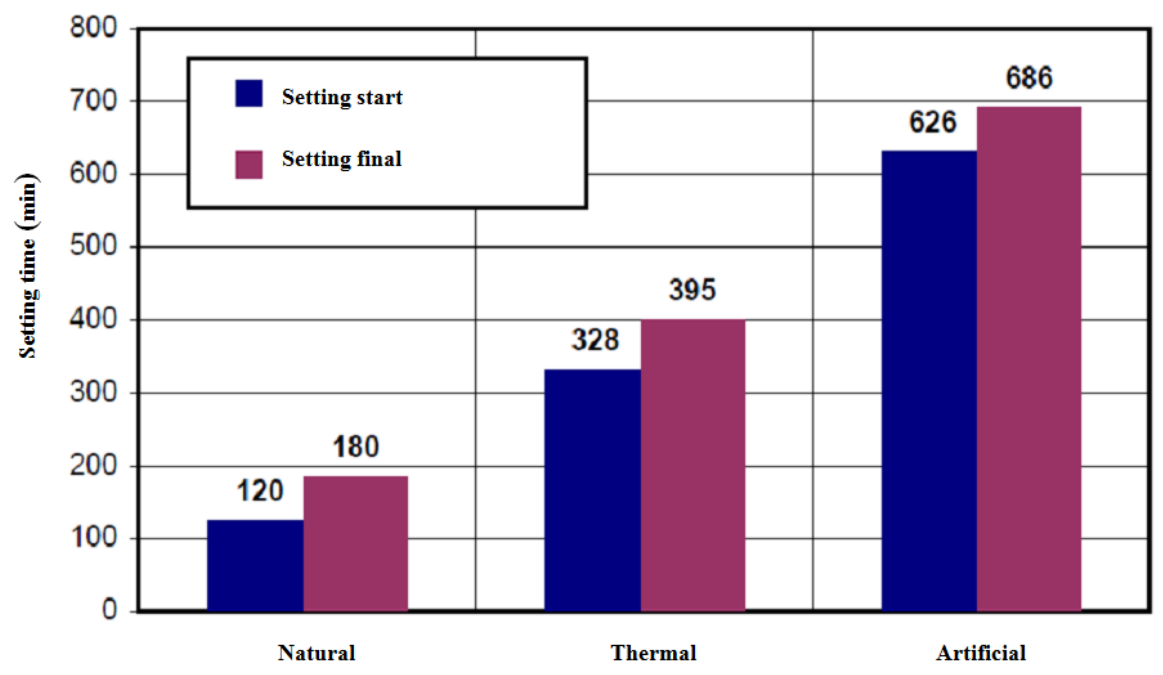

Fig. 1. Values of setting time depending on the type of anhydrite. 


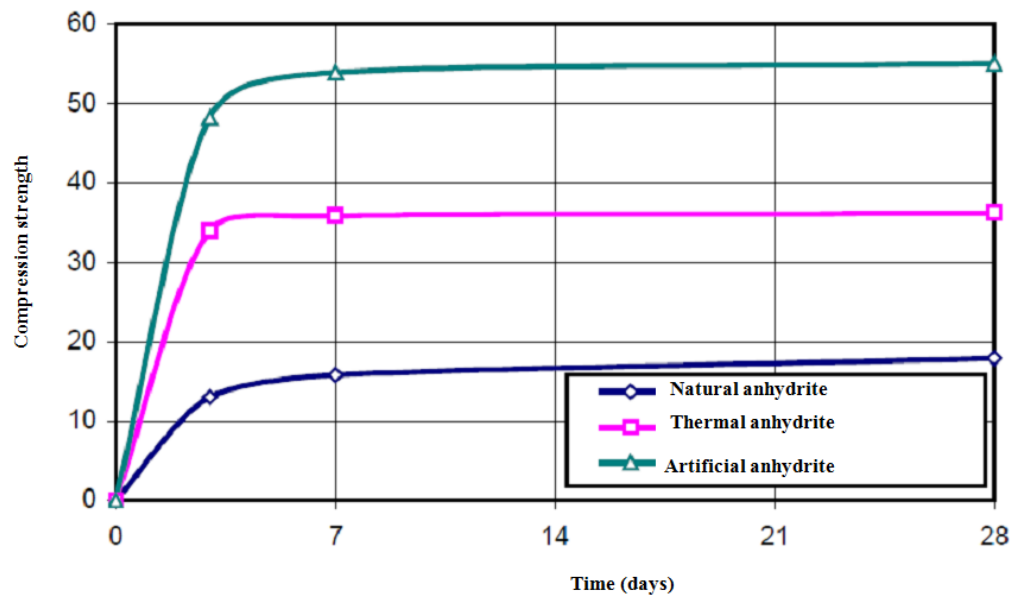

Fig. 2. Compressive strength of various types of anhydrites.

The obtained research results revealed that the most perspective anhydrite for the further researches and usage in filling mixtures is an artificial one.

In order to use the artificial anhydrite as a binder in the manufacture of filling mixtures, their properties, which are given in Tables 1 and 2, should be ensured. Provision of technological, physic and mechanical properties of such filling mixtures can be achieved by directional modification of artificial anhydrite with various activators. Table 3 shows the research results of the properties of artificial anhydrite with various types and contents of additives. The analysis of the obtained results revealed that the optimum modifying additive is a mixture of an alkaline activator (portland cement) and a sulfate one (potassium sulfate), which provides the required time for initial hardening of the activated artificial anhydrite.

Table 1. Technological properties of filling mixtures.

\begin{tabular}{|l|c|}
\hline $\begin{array}{c}\text { Standardized values of filling mixtures (without a coarse aggregate } \\
\text { or with a fine aggregate content) }\end{array}$ & Value \\
\hline Slump of the standard cone (complete immersion) & $9.0-14.0 \mathrm{~cm}$ \\
\hline Spreadability of mixture from Southard viscosimeter & $13-20 \mathrm{~cm}$ \\
\hline Delaminatability index & no more than 1.3 \\
\hline Mixture setting & no less than $2 \mathrm{~h}$ \\
\hline Water segregation from filling mass & no more than $2 \%$ \\
\hline
\end{tabular}

Table 2. Filling mixture strength depending on size of the excavation.

\begin{tabular}{|c|c|c|c|c|}
\hline \multirow{2}{*}{$\begin{array}{c}\text { Excavation } \\
\text { height, } \mathrm{m}\end{array}$} & \multirow{2}{*}{$\begin{array}{c}\text { Characteristic } \\
\text { strength, MPa }\end{array}$} & \multirow{2}{*}{$\begin{array}{c}\text { Excavation span } \\
\text { width, } \mathrm{m}\end{array}$} & \multicolumn{2}{|c|}{ Characteristic strength, MPa } \\
\cline { 4 - 5 } & (assurance factor 3) & $\begin{array}{c}\text { (assurance factor } \\
\text { 2) }\end{array}$ \\
\hline$<10$ & 1.0 & 6 & 4 & 3 \\
\hline$<20$ & 1.5 & 7 & 5 & 4 \\
\hline$<30$ & 2.0 & 8 & 6 & 5 \\
\hline$<40$ & 2.5 & 9 & 7 & 6 \\
\hline$<50$ & 3.0 & 10 & 8 & 7 \\
\hline
\end{tabular}

In order to determine the optimal content of modifiers in the developed anhydrite binder, the mathematical planning of the experiment was used for the producing of filling mixtures. The adopted factors (CEM I 42,5 and $\mathrm{K}_{2} \mathrm{SO}_{4}$ ) and the levels of their variability are given in Table 4. 
Table 3. Properties of artificial anhydrite with hardening activators

\begin{tabular}{|c|c|c|c|c|c|}
\hline \multirow{2}{*}{ № } & \multicolumn{2}{|c|}{ Accelerating agent } & \multirow{2}{*}{$\begin{array}{c}\mathrm{W} / \mathrm{A} \\
\%\end{array}$} & \multicolumn{2}{|c|}{ Setting time, h-min } \\
\hline & Type & Amount, $\%$ & & Start & End \\
\hline 1 & No agent & -- & 28 & \multicolumn{2}{|c|}{ Doesn't set } \\
\hline \multirow{2}{*}{2} & CEM I 42,5 & 5 & \multirow{2}{*}{48} & \multirow{2}{*}{$1-10$} & \multirow{2}{*}{$2-30$} \\
\hline & $\mathrm{K}_{2} \mathrm{SO}_{4}$ & 2 & & & \\
\hline \multirow{2}{*}{3} & CEM I 42,5 & 2.5 & \multirow{2}{*}{41} & \multirow{2}{*}{$1-10$} & \multirow{2}{*}{$2-50$} \\
\hline & $\mathrm{K}_{2} \mathrm{SO}_{4}$ & 2 & & & \\
\hline \multirow{2}{*}{4} & CEM I 42,5 & 2.5 & \multirow{2}{*}{40} & \multirow{2}{*}{$1-50$} & \multirow{2}{*}{$3-00$} \\
\hline & $\mathrm{K}_{2} \mathrm{SO}_{4}$ & 1 & & & \\
\hline \multirow{2}{*}{5} & $\mathrm{Ca}(\mathrm{OH})_{2}$ & 0.3 & \multirow{2}{*}{39} & \multirow{2}{*}{$0-50$} & \multirow{2}{*}{$1-50$} \\
\hline & $\mathrm{K}_{2} \mathrm{SO}_{4}$ & 1 & & & \\
\hline
\end{tabular}

Table 4. Properties of artificial anhydrite with hardening activators

\begin{tabular}{|c|c|c|c|c|}
\hline \multirow{2}{*}{ Factors } & \multirow{2}{*}{ Notation } & \multicolumn{3}{|c|}{ Variability levels } \\
\cline { 3 - 5 } & & -1 & 0 & +1 \\
\hline $\begin{array}{c}\text { Content of portland cement CEM I 42,5,\% by } \\
\text { weight of binder }\end{array}$ & $\mathrm{X}_{1}$ & 2.0 & 3.5 & 5.0 \\
\hline Content of $\mathrm{K}_{2} \mathrm{SO}_{4}, \%$ by weight of binder & $\mathrm{X}_{2}$ & 0.5 & 1.25 & 2,0 \\
\hline
\end{tabular}

As a result of the conducted experiment, mathematical models (regression equations) were obtained according to the number of determinable characteristics (setting start, compressive strength at the age of 1 and 7 days) with significant factors for the adopted variables:

$$
\begin{gathered}
\text { S.S. }=117.52-25.3 \cdot \mathrm{X} 2+6.25 \cdot \mathrm{X} 1 \cdot \mathrm{X} 2-3.7 \cdot \mathrm{X} 12-19.7 \cdot \mathrm{X} 22, \\
\mathrm{R} 1=3.89-0.45 \cdot \mathrm{X} 1+0.47 \cdot \mathrm{X} 2-0.58 \cdot \mathrm{X} 1 \cdot \mathrm{X} 2-0.68 \cdot \mathrm{X} 12-0.23 \cdot \mathrm{X} 22, \\
\mathrm{R} 7=16.9-2.07 \cdot \mathrm{X} 1-1.08 \cdot \mathrm{X} 2-0.25 \cdot \mathrm{X} 1 \cdot \mathrm{X} 2-2.63 \cdot \mathrm{X} 12-2.08 \cdot \mathrm{X} 22
\end{gathered}
$$

According to the graphical construction of the received mathematical models shown in Figure 3, for the setting start of the binding agent and for its strength at the age of 7 days it was determined that the optimum composition of the anhydrite binder modifier, which ensures the correspondence with the demands raised on the binder for filling mixtures, contains CEM I 42,5 at a rate of $2.5 \%$ of binder mass and $1 \%$ of $\mathrm{K}_{2} \mathrm{SO}_{4}$. The binder with this modifier was adopted as the default one for further development of filling mixtures.

a)

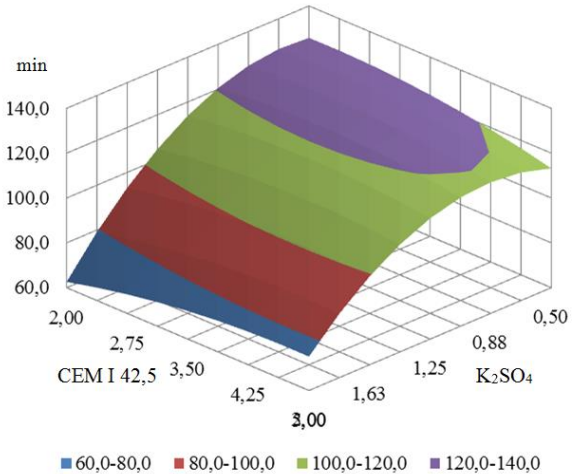

b)

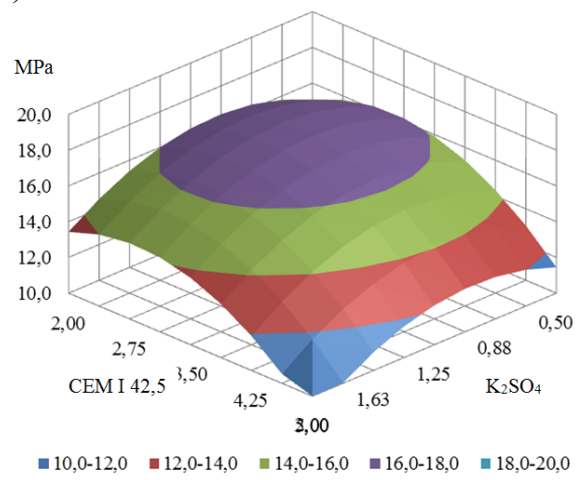

Fig. 3. Correlation between the binder setting start (a), the compressive strength at the age of 7 days (b) and the content of Portland cement and potassium sulfate. 
Additional modification of the binder was conducted with plasticizing additives, the most efficient additive was Melment F10, injected in an amount of 0.4 to $1 \%$ of the binder mass. For the further assessment of the structure of the obtained binder with different contents of the Melment F10 plasticizer, additional structural studies were conducted using the focused beam microscope, also studies of mineral composition using the powder diffractometry were conducted. Table 5 shows the study results of the mineral composition of solidified samples based on synthetic anhydrite.

Table 5. Mineral composition of samples.

\begin{tabular}{|l|c|c|c|c|}
\hline & Composition & \multicolumn{3}{|c|}{ Mineral content, \% } \\
\cline { 3 - 5 } & $\mathrm{CaSO}_{4}$ & $\mathrm{CaSO}_{4} \cdot 2 \mathrm{H}_{2} \mathrm{O}$ & Silex \\
\hline 1 & $\begin{array}{c}\text { CEM I 42,5 2.5\%, } \\
\mathrm{K}_{2} \mathrm{SO}_{4} 1 \%\end{array}$ & 54.2 & 45.0 & 0.8 \\
\hline 2 & $\begin{array}{c}\text { CEM I 42,5 2.5\%, } \mathrm{SO}_{2} 1 \%, \\
\text { Melment F10 - 0,7 \% }\end{array}$ & 40.7 & 58.6 & 0.6 \\
\hline 3 & $\begin{array}{c}\text { CEM I 42,5 2.5\%, } \mathrm{K}_{2} \mathrm{SO}_{4} 1 \%, \\
\text { Melment F10 - 0,4 \% }\end{array}$ & 40.8 & 58.5 & 0.6 \\
\hline $\begin{array}{c}\text { CEM I 42,5 2.5\%, } \\
\mathrm{K}_{2} \mathrm{SO}_{4} 1 \%, \text { Melment F10 - 1 \% }\end{array}$ & $\mathbf{4 5 . 6}$ & $\mathbf{5 3 . 8}$ & $\mathbf{0 . 6}$ \\
\hline
\end{tabular}

For the further assessment of the structure of received binder with various Melment F10 plasticizer contents, additional structural studies were carried out using focused beam microscope.

A reference sample without a plasticizing additive is characterized by the lowest reactivity, the content of the calcium sulfate dehydrate is $45 \%$, and the content of unreacted anhydrite is $54 \%$, which determines its minimal physical mechanical characteristics. Decreasing the water-binder ratio by the means of reduction of the plasticizer content to 0.4 and $0.7 \%$ leads to the increase of the binder reactivity, to the decrease of anhydrite content to $41 \%$, and also to the increase of calcium sulfate dehydrate content to $59 \%$. Such ratio of minerals leads to the development of crystals of comparable sizes, and as a result, to the increase of strength and water resistance. The most desirable characteristics of the modified anhydrite binder are provided when the plasticizing additive Melment F10 is added in an amount of $1 \%$ due to the optimum content of anhydrite and calcium sulfate dehydrate in an amount of 46 and $54 \%$ respectively. The structure with the maximum strength and with the crystals of various shapes is developed at the given ratio of anhydrite and calcium sulfate dehydrate, in which anhydrite serves as a reinforcement cage, and a calcium sulfate dehydrate serves as a binder matrix.

As a result of the conducted research, an effective binder based on an artificial anhydrite was obtained, which can be used for the development of various types of filling mixes [13$16]$.

\section{Evaluation}

Selecting the composition of the filling mixtures with the retrained binder based on the synthetic anhydrite was carried out by the means of selecting the optimum amount of sand, while ensuring the required mobility and other properties. As a result of the conducted research, two mixture compositions are determined, which correspond to the design technological, physical and mechanical properties required for filling mixtures. Technological properties, composition and strength parameters of the developed filling mixtures are presented in Table 6. 
Table 6. Composition and properties of filling mixtures.

\begin{tabular}{|c|l|c|c|}
\hline № & \multicolumn{1}{|c|}{ Mixture composition, $\mathrm{kg} / \mathrm{m}^{3}$} & Composition 1 & Composition 2 \\
\hline 1 & Cement & 0 & 22 \\
\hline 2 & Modified anhydrite binder & 740 & 840 \\
\hline 3 & Sand & 1110 & 840 \\
\hline 4 & Water & 350 & 370 \\
\hline \multicolumn{2}{|c|}{ Properties of stowing mixtures } \\
\hline 5 & Density, $\mathrm{kg} / \mathrm{m}^{3}$ & 2150 & 2040 \\
\hline 6 & Cone slump, cm & 14 & 14 \\
\hline 7 & Southard Spreadability, cm & 12 & 12 \\
\hline 8 & Spread on the jolting table (15 jolts), cm & 20 & 21 \\
\hline 9 & Water gain, \% & 0.5 & 0.1 \\
\hline 10 & Compression strength 1 day MPa & $3.0 \ldots 5.3$ & $6.0 \ldots 11.1$ \\
\hline 11 & Compression strength (7 day, dry), MPa & $10.0 \ldots 10.7$ & $15.1 \ldots 24.1$ \\
\hline 12 & Compression strength (7 day, water saturated), MPa & $5.2 \ldots 6.4$ & $8.3 \ldots 14.5$ \\
\hline 13 & Softening facor & $0.52 \ldots 0.6$ & $0.55 \ldots 0.6$ \\
\hline
\end{tabular}

The obtained research results have shown an opportunity and a prospectivity of application of the modified synthetic calcium sulphate in the composition of filling mixtures. The use of various local aggregates (coarse and fine) in the development of filling mixture compositions with various grades based on modified synthetic anhydrite gives the opportunity to achieve the results received in this study, and in some cases to achieve even better results.

\section{Conclusions}

1. The capability of using the artificial anhydrite based on industrial wastes in the filling mixtures is substantiated.

2. The optimum modified additive is determined to be a mixture of an alkaline activator in the form of Portland cement and a sulfate activator in the form of potassium sulfate, which corresponds the required time for the initial hardening of the synthetic anhydrite.

3. Models which determine the correlation between the properties of the binder based on natural anhydrite, such as setting time and compressive strength at the age of 1 and 7 days, and the content of activators were obtained.

4. The optimum mineral composition of a strong and water-resistant binder based on synthetic anhydrite containing $46 \%$ of anhydrite and $54 \%$ of calcium sulfate dehydrate is determined, the composition presumes the formation of the strongest structure with crystals of various shapes, the anhydrite serves as a reinforcement cage, and the calcium sulfate dehydrate as a binding matrix .

5. Compositions of effective filling mixtures based on the obtained modified binder made of artificial anhydrite have been developed. The developed compositions of effective filling mixes on the basis of artificial anhydrite are advisable to be used for the production of filling mixtures with a design strength of more than $10 \mathrm{MPa}$ in excavations with maximum dimensions.

\section{References}


1. H.-B. Fisher, B. Vtorov, II International meeting on chemistry and technology of cement. Survey reports 2, 53 (2000)

2. M. Naftal, I. Ilyukhin, R. Shestakova, A. Kozlov, Non-ferrous metals 8, 41 (2009)

3. Ch. Riechert, F. Riechert, H.-B. Fischer, III of the All-Russian scientific and practical conference. Northeast federal university of M.K. Ammosov, 400 (2014)

4. A. Grinevich, A. Kiselev, E. Kuznetsov, A. Buryanov, Construction Materials 11, 16 (2013)

5. A. Grinevich, A. Kiselyov, A. Buryanov, E. Kuznetsov, V. Moshkova, Patent of the Russian Federation \#82445267 (2012)

6. E. Korneeva, Global scientific potential 19, 171-174 (2012)

7. M. Ageeva, D. Sopin., A. Ginzburg., N. Kalashnikov, G. Lesovik, Bulletin of the Belgorod state technological university of V.G. Shukhov 4, 43 ( 2013)

8. R. Lesovik, M. Ageev, G. Bogusevich, D. Sopin, Bulletin of the Belgorod state technological university of V.G. Shukhov 12, 31 (2016)

9. V. Belov, A. Buryanov, G. Yakovlev, Modification of structure and properties of construction composites on the basis of calcium sulfate (2012)

10. V. Petropavlovskaya, V. Belov., T. Novichenkova, A. Buryanov, A. Pustovgar, Construction materials 7, 22 (2010)

11. V. Petropavlovskaya, A. Buryanov, T. Novichenkova, G. Yakovlev, Construction materials 1-2, 42 (2014)

12. Yu. Tokarev, E. Ginchitsky, Yu. Ginchitskaya, A. Gordina, G. Yakovlev, Construction materials 1-2, 84 (2016)

13. N. Galtseva, A. Buryanov, E. Buldyzhova, Scientific review 22, 157 (2015)

14. A. Buryanov, N. Galtseva, E. Buldyzhova, V. Solovyov, Construction materials 6, 76 (2015)

15. N. Galtseva,A. Buryanov Construction materials 7, 33 (2016)

16. A. Buryanov, N. Galtseva, V. Solovyov, D. Tkachenko, Construction materials 8, 74 (2017) 